\title{
Formação de professores em foco: Breve panorâmica histórica, acesso e permanência
}

\author{
Teacher training in focus: Brief historical overview, access and permanence \\ La formación del profesorado en evidencia: Breve síntesis histórica, acceso y permanencia
}

Recebido: 19/07/2021 | Revisado: 25/07/2021 | Aceito: 26/07/2021 | Publicado: 01/08/2021

Gerson Avelino Fernandes Pereira
ORCID: https://orcid.org/0000-0003-0536-5861
Instituto Federal de Educação, Ciência e Tecnologia do Norte de Minas Gerais, Brasil
E-mail: gerson.pereira@ifnmg.edu.br
Gilmara Gonçalves Santos
ORCID: https://orcid.org/0000-0002-2617-0134
E-mail: gilmara.santos@ifnmg.edu.br

\section{Resumo}

Parece clichê falar sobre formação de professores, mais precisamente sobre as políticas de formação docente. Durante anos o curso de licenciatura esteve sob vários enfoques, transmutando entre objetivos, práticas, currículos e perfis profissionais diferentes, ao sabor de ideários vigentes que correspondessem às necessidades transitórias de governos. Hodiernamente, alguns avanços aconteceram em termos do repensar das licenciaturas sob uma ótica do acesso e permanência, mas ainda há muitas lacunas a serem deslindadas. Assim, a partir de um levantamento bibliográfico, este estudo objetivou discutir questões acerca da docência através de uma breve panorâmica sobre sua existência, algumas diferenciações necessárias entre a licenciatura e o bacharelado procurando consolidar uma identidade como sendo dotada dos mesmos rigores que os outros cursos de graduação. E, por fim, apontar algumas políticas de fortalecimento da procura, entrada e permanência na área de educação numa perspectiva propositadamente superficial, a fim de provocar o debate em dimensões mais amplas futuramente. Pôde-se constatar então que, apesar de uma gênese bastante superficial e o arrefecimento de discursos de valorização da docência ao longo da história, a formação de professores sempre passou por uma linha tênue entre concepções emancipatórias e mecanicistas, mas, segue resistindo na afirmação de sua identidade e marcada pela imprescindibilidade de estar no centro dos debates em nível micro e macro.

Palavras-chave: Licenciaturas; Políticas; Acesso e permanência.

\begin{abstract}
It seems a cliché to talk about teacher training, more precisely about teacher education policies. For years, the degree course has been under different approaches, transmuting among different objectives, practices, curricula and professional profiles, according to current ideas that correspond to the transitory needs of governments. Currently, some advances have taken place in terms of rethinking degrees from the perspective of access and permanence, but there are still many gaps to be unraveled. Thus, from a bibliographical survey, this study aimed to discuss issues about teaching through a brief overview on its existence, some necessary differences between the degree and the baccalaureate, seeking to consolidate an identity as being endowed with the same rigors as other courses of graduation. And, finally, to point out some policies to strengthen demand, entry and permanence in the area of education in a purposefully superficial perspective in order to provoke debate in broader dimensions in the future. It could be verified then that, despite a very superficial genesis and the cooling of discourses of valuing teaching throughout history, teacher training has always gone through a fine line between emancipatory and mechanistic conceptions, but it continues to resist in the affirmation of its identity is marked by the indispensability of being at the center of debates at the micro and macro levels.
\end{abstract}

Keywords: Degrees; Policies; Access and permanence.

\section{Resumen}

Parece cliché hablar de formación del profesorado, más concretamente de políticas de formación del profesorado. Desde hace años los cursos de graduación se encuentran bajo diversos enfoques, transmutándose entre diferentes objetivos, prácticas, currículos y perfiles profesionales, en el gusto de las ideas actuales que corresponden a las necesidades transitorias de los gobiernos. Hoy en día, se han producido algunos avances en cuanto al replanteamiento de las titulaciones desde una perspectiva de acceso y permanencia, pero aún quedan muchas brechas por deshacer. Así, a partir de un estudio bibliográfico, este estudio tuvo como objetivo discutir cuestiones sobre la enseñanza a través de una breve visión general de su existencia, algunas diferenciaciones necesarias entre la licenciatura y el bachillerato, buscando consolidar una identidad como avalada con los mismos rigores que los otros cursos de graduación. Y, por último, señalar algunas políticas de fortalecimiento de la demanda, la entrada y la permanencia en el ámbito de la educación en una perspectiva deliberadamente superficial para provocar el debate en dimensiones más amplias en el futuro. Se observó entonces que, a pesar de una génesis más bien superficial y del enfriamiento de los discursos de valorización de la enseñanza a lo largo de la historia, la formación docente siempre ha cruzado una delgada línea entre las concepciones 
emancipatorias y mecanicistas, pero sigue resistiendo la afirmación de su identidad y marcada por la imprescindibilidad de estar en el centro de los debates a nivel micro y macro.

Palabras clave: Licenciaturas; Políticas; Acceso y permanência.

\section{Introdução}

Até os dias atuais ainda se coloca em discussão os cursos de licenciatura de um modo geral, visando o entendimento dos paradigmas que cercam os mesmos. Com seu caráter formativo e preparatório no que diz respeito à docência, divide opiniões sobre como vem sendo trazido e concebido no cenário vigente, considerando as intempéries intrínsecas ao longo de sua consolidação e das reformas que hoje possibilitam a construção da identidade da licenciatura na rede pública de ensino.

Existe por trás de todo o contexto em que se inserem os cursos de formação de professores hoje, inúmeros momentos de lutas e incertezas, onde a face destes foi reestruturada seguindo alguns ideários impostos pela sociedade que comandava todas as instâncias em que pudessem disseminar as ideologias subjacentes às suas políticas.

A saga das licenciaturas nas instituições públicas enfrentou diversas crises de existência, nas quais ora o acesso a esses cursos era incentivado e alvo de investimento do poder público, ora os estudantes dos mesmos eram alvo das estatísticas de evasão devido ao baixo investimento, manutenção e ausência de um currículo realmente formador, que fizesse a diferença.

Quando se discute formação docente no Brasil, é preciso elencar vários fatores que desestimulam o interesse por ela, e escancaram essa realidade de falta de professores na educação básica, que é escopo de várias discussões relatadas na literatura.

A exemplo disso, Pereira (1999, p. 111) ressalta que:

[...] são vários os fatores externos ao processo pedagógico que vêm prejudicando a formação inicial e continuada dos professores no país, destacando-se o aviltamento salarial e a precariedade do trabalho escolar. Sabe-se que o desestímulo dos jovens à escolha do magistério como profissão futura e a desmotivação dos professores em exercício para buscar aprimoramento profissional são consequência, sobretudo, das más condições de trabalho, dos salários pouco atraentes, da jornada de trabalho excessiva e da inexistência de planos de carreira.

Nesse patamar consegue-se identificar alguns elementos que tornam a profissão em si, menos ansiada a cada dia, mas, é de suma salientar o que vem antes da prática docente como ofício, o processo formativo que se percorreu para chegar até ali, os ambientes formadores nos quais se originou o arcabouço do saber sistematizado, as concepções de ensino e, mormente, as políticas que guarneceram a formação do profissional.

E com o objetivo de proporcionar uma clarificação panorâmica acerca dos aspectos políticos e educacionais que envolvem a formação para o magistério superior, propõe-se com esse estudo de levantamento bibliográfico, buscar na literatura alguns pontos da historicização da licenciatura enquanto curso de formação de professores, os desafios enfrentados relativos à segregação perante os outros cursos superiores (Bacharelado) e as iniciativas do poder público com vistas à redesenhar a licenciatura no sentido de produção de ciência, acesso e permanência, sem qualquer pretensão de um esgotamento no assunto.

\section{Metodologia}

O presente artigo se caracteriza por constituir-se a partir de uma pesquisa bibliográfica a partir de Severino (2007, p. 122), que esclarece que este “[...] se realiza a partir do registro disponível, decorrente de pesquisas anteriores, em documentos impressos, como livros, artigos, teses, etc. [...] Os textos tornam-se fontes dos temas a serem pesquisados.” Assim, optou-se por iniciar uma discussão acerca da formação de professores de forma generalista, na tentativa de subsidiar uma nova roupagem para velhos embates que se entremeiam em lacunas até os dias atuais.

A investigação foi enveredada pela importância de uma análise diacrônica, alijando nesse momento de qualquer equacionamento, com vistas a uma abordagem qualitativa. Quanto a este tipo de abordagem, Martins (2010) nos alerta que a 
mesma prescinde de procedimentos metódicos e quantificadores. Ainda acrescenta Godoy (1995) que a mesma não se prende a formas estruturadas de propostas de pesquisa, pois a mesma se caracteriza por abrir espaço para que a criatividade do pesquisador e a sua imaginação possa levá-lo a explorar novos olhares acerca do tema pesquisado.

\section{Resultados e Discussão}

\subsection{O curso de formação de professores: um pouco de história}

A tarefa de formar professores não se resumiu apenas na criação de cursos de magistério ao longo da história, pelo contrário, a profissionalização superior da atividade docente começou a acontecer quando esta prática já estava consideravelmente consolidada. Segundo Guedes e Ferreira (2002, p. 1):

Os primeiros cursos de formação de professores, em termos de licenciatura, surgiram no Brasil nos anos 30 (séc. XX) com a criação das Faculdades de Filosofia, Ciências e Letras. No período compreendido entre 1931 a 1939 foram criadas novas unidades de ensino nos diferentes projetos de Universidade, incluindo-se nesse contexto vários modelos de organização das unidades voltadas especificamente para o processo de formação de professores.

Verifica-se nesse contexto que o status de curso universitário só foi atribuído à formação docente na segunda metade do século XX, mas é relevante colocar em pauta que, no Brasil, a necessidade de capacitação para o ofício de lecionar já era sentida há aproximadamente um século antes. Nas palavras de Penin (2002, p.1) “os primeiros cursos de formação de professores para o ensino primário se estabeleceram em algumas capitais a partir de 1835, em nível secundário, com duração máxima de dois anos."

Nesse ínterim estabelecido entre os primeiros cursos até o patamar de licenciatura, deve-se levar em conta que a atividade docente não ficou estagnada, existiam professores e indivíduos que precisavam ser educados, o exercício político fluindo e toda a rotina de uma sociedade em vigor, e, queira ou não, as linhas de pensamento tanto individual como social iam se renovando, o que passava a exigir cada vez mais um saber sistematizado e com novas tendências de formação, dificultando o entendimento do porquê de uma demora colossal em atribuir a importância da preparação docente em universidade.

Após esse período de incipiência das licenciaturas, cortamos o percurso e nos ateremos a alguns momentos importantes da história da formação docente. A começar pela década de 1970, que, por influência dos ideários do regime militar circundantes na época, trouxe ao cenário educacional uma tendência em que o direito ao pensamento e criação de condições para que os indivíduos se tornassem sujeitos inovadores era suplantado por uma vertente altamente funcional e utilitarista, de caráter técnico e executável, sintetizado nas palavras de Candau (1982 como citado em PEREIRA, 2000, p. 16) quando ela diz que:

Na primeira metade da década de 70, sob influência da psicologia comportamental e da tecnologia educacional, a maioria dos estudos privilegiava a dimensão técnica do processo de formação de professores e especialistas em educação. Nessa perspectiva, o professor era concebido como um organizador dos componentes do processo de ensinoaprendizagem (objetivos, seleção de conteúdo, estratégias de ensino, avaliação, etc.) que deveriam ser rigorosamente planejados para garantir resultados instrucionais altamente eficazes e eficientes. Consequentemente, a grande preocupação, no que se refere à formação do professor, era a instrumentalização técnica.

Sob esta ótica, percebe-se a função do professor como um técnico, e para tanto, a sua formação era embasada nesse pilar, o que nos leva a crer na licenciatura como sendo alijada de relações dialógicas sobre o tipo de professor que estava se formando, o papel desse profissional frente à sociedade, o poder transformador da educação, dentre outros; construindo um profissional com identidade executora e não criadora. Basta se atentar para as Leis de Diretrizes e Bases da Educação Nacional de 1961 e 1971, 4.024/61 e 5692/71 respectivamente, que, pouco se comprometeram com qualidade da educação básica, estabelecendo níveis e habilitações diferentes para o professor de cada etapa de ensino, preconizando o ajustamento ao 
desenvolvimento das características dos conteúdos e o atendimento ao crescimento da economia, e, com isso, denota-se também as disparidades salariais.

Com essa rápida passagem pela formação docente dos anos 70, inicia-se a década de 1980, com novos ideários de educação, a licenciatura que antes formava um profissional treinado para resolver problemas apontando soluções técnicas para as possíveis falhas no processo educativo passou a corroborar o pensamento de que, para além de um professor, necessitava-se atribuí-lo a função de educador, e esperar deste a capacidade de transformar o cenário educacional apenas com sua práxis, numa perspectiva bastante enraizada numa matriz redentora de educação (Luckesi, 2011).

Esperar do professor ou do licenciando (futuro professor) que ele reinvente sua prática tornando-a cada vez mais eficaz não seria a problemática aqui, mas sim, o fato de o mesmo carregar sobre si o peso de uma política pública que inclui inúmeros outros sujeitos, o que nos leva a pensar numa década bastante contraditória e paradoxal para a educação.

Para efeito de exemplificação, as palavras de Freitas (2002, p.139) traduzem o lado positivo desses anos de luta (década de 80), quando ressalta que:

Os anos 80 representaram a ruptura com o pensamento tecnicista que predominava na área até então. No âmbito do movimento da formação, os educadores produziram e evidenciaram concepções avançadas sobre formação do educador, destacando o caráter sócio-histórico dessa formação, a necessidade de um profissional de caráter amplo, com pleno domínio e compreensão da realidade de seu tempo, com desenvolvimento da consciência crítica que lhe permita interferir e transformar as condições da escola, da educação e da sociedade. Com esta concepção emancipadora de educação e formação, avançou no sentido de buscar superar as dicotomias entre professores e especialistas, pedagogia e licenciaturas, especialistas e generalistas, pois a escola avançava para a democratização das relações de poder em seu interior e para a construção de novos projetos coletivos. Como parte importante desta construção teórica a partir das transformações concretas no campo da escola, construiu a concepção de profissional de educação que tem na docência e no trabalho pedagógico a sua particularidade e especificidade. (grifo do autor).

Por outro lado, Nagle (1986 como citado em PEREIRA, 2000, p. 28) traz à baila de forma muito clara, o descontentamento com aquilo que é arraigado nos discursos, mas que resulta na prática de forma pífia, discorrendo que:

Já vem causando um pouco de irritação o uso indiscriminado da palavra educador, porque neste país nem se forma o professor direito e já se julga que se deve, em lugar de professor, formar educador. Outra palavra mágica esta, que já faz parte da linguagem comum, sem que se saiba bem o que é o educador.

É percebível com relação aos discursos supraditos que, a formação docente na década de 80 passou por um momento de ressignificação, onde os debates estavam em torno da autonomia, em que a formação atribuída nos cursos de licenciatura contemplasse não só a dimensão prática, com o ensino de execução de funções preestabelecidas, mas que, o poder de indagação e reformulação de conceitos através dos saberes acadêmicos fosse instigado, o que deixou a desejar da maneira equivocada como aconteceu.

Com toda a amplitude do discurso formativo da década anterior, a década de 90 entra em cena, com um ímpeto a mais de ruptura de tentativas mal sucedidas, na busca por um professor que pensasse sua prática e a concebesse num processo de pesquisa, de procura pela melhor metodologia, a eficácia do ensino, a construção do saber e tantos outros pontos norteadores da práxis docente.

Quando se sai de uma década onde fica evidente o peso do processo educacional sobre a sua prática, a formação do professor encontra-se assoberbada de funções que em nada se convergem para seu ofício central de ser agente na construção do conhecimento e na formação humanística dos sujeitos, de levar o aluno à busca pelo ainda não descoberto, e isso faz com que a necessidade da recorrência a outras fontes de clarificação de dúvidas e captação de novas informações se emirja, dando assim um pontapé crucial no discurso formativo de professores na época, colocando em cena a pesquisa como indissociável ao mesmo. 
Nessa perspectiva, Correa (2011, p. 4) explica que:

[...] na década de 90 temos o professor pesquisador, que concomitantemente realiza atividades de pesquisa, teoria e atividade docente, pratica pedagógica. Assim, temos o professor, que exerce um papel imprescindível e insubstituível para a construção e socialização dos saberes que são intrínsecos à construção do conhecimento.

Mas, conforme alerta Saviani (1983), precisamos fazer uma travessia, de um conhecimento ingênuo em direção a outro, que se constitui filosófico e crítico em sua gênese, assim, é necessário que as interpretações de mundo e de sociedade não se deem no campo do obscurantismo e embasado num amontoado de senso comum pedagógico, pois, por mais que seja necessária a polivalência desse profissional docente, esta não se faz sozinha e desprovida de intencionalidade de políticas públicas de formação destinadas à mesma.

Dessa forma, estabelecer o perfil de professor pesquisador como sendo altamente exequível ao sistema educativo tem suas contradições, mas, não se pode olvidar que, a importância do ato de pesquisar atribui ao docente o direito de conduzir sua prática de acordo as características do seu alunado, dos sujeitos que ali estão e necessitam de conhecimento de forma que contemple sua realidade.

De posse dessas tendências emancipatórias de formação docente, os anos 90, com todas as ambivalências, configuraram uma divisão de águas em termos de licenciaturas, o que trouxe para esses cursos dessa época até os dias atuais, a emergência em se discutir educação intrinsecamente ligada à pesquisa; ao professor não basta mais somente à racionalidade técnica, a eficiência na resolução de problemas, a abrangência de sua função ao status de educador ou até mesmo a detenção do saber, pelo contrário, urge a esse profissional o repensar de suas práticas e a inclusão de novas fontes de construção do saber no seu cotidiano.

\subsection{Licenciatura versus bacharelado: uma diferenciação necessária na afirmação da identidade da formação docente}

Os cursos de formação superior no Brasil passaram por grandes reformas ao longo do tempo e com isso estabeleceu-se algumas divisões entre os mesmos, classificando-os segundo a função para a qual se pretende formar e os campos de atuação concernentes aos mesmos.

A trajetória acadêmica daqueles que se propõem obter uma formação superior é marcada por grandes diferenças entre este ou aquele curso, e cabe às instituições de ensino fazer com que as peculiaridades de cada área sejam respeitadas, seguindo suas legislações específicas, caracterizando um exercício de alteridade onde todas tem sua importância ímpar.

Essa dicotomia nas áreas de formação também se faz presente quando o eixo norteador de um discurso está incluído nas equiparações entre licenciaturas e bacharelados. Estes se constituem uma preparação para o exercício de um ofício inerente ao que foi cursado em uma instituição de ensino superior, já aquelas preconizam e têm como escopo o ato de lecionar, ou seja, ensinar algo que se aprendeu relativo a alguma área, não olvidando as perspectivas críticas de formação e o papel social e político deste tipo de curso.

Para que fiquem claros os conceitos expostos acima, Silveira e Silva (2009, p. 2) ressaltam que:

[...] aqueles alunos que desejarem atuar como Professores na Educação Básica devem procurar frequentar o curso de LICENCIATURA, e aqueles outros que desejarem atuar nas demais áreas de trabalho, devem procurar cursos superiores de Bacharelado, estando claro que um formado em curso de licenciatura não poderá atuar na área do formado em curso de "bacharelado" e vice versa.

Apesar de estarmos situados num país onde o ecletismo se faz presente e as diferenças se configuram uma marca cultural, quando a necessidade de opção pela licenciatura ou pelo bacharelado entra em cena, as dúvidas ainda são impeditivas para que a efetividade dessa tomada de decisão aconteça em plenitude, seja pela exequibilidade de cada um ou pelo atendimento às expectativas do indivíduo. 
O grande aspecto a ser levado em conta nessas situações é o projeto de vida de cada ser que se propõe a uma formação superior, a pretensão em torno dos itinerários que aquele tipo de curso irá levar, seja numa perspectiva urgente ou postergada, porque é a partir daí que se podem reputar as inúmeras possibilidades existentes nos entornos e delinear a mais próxima de suas vontades e necessidades, através de uma análise conjuntural dos fatos e da realidade (Souza, 2014).

A escolha por estar na licenciatura não deve ser desmerecida ou até mesmo estar atrelada como falta de opção ou falta de oportunidade, uma vez que, como os outros modelos de formação superior, a mesma requer compromisso e competência no exercício da formação acadêmica e no mundo do trabalho, não olvidando a importância do reconhecimento em relação a política salarial, pois ao docente recai densas responsabilidades como a de atualização científica e cultural (Libâneo, 2011) e em hipótese alguma deve perder o seu caráter de profissionalidade.

Nessa disputa ideológica se torna relevante chegar um consenso, passando da síncrese à síntese, seja licenciatura ou bacharelado, todos, independentemente do seu foco trabalhista e empregatício, são feitos a partir de uma escolha, diferentemente de quaisquer das etapas de educação básica que são obrigatórias, e isso se faz de maneira pensada e reflexiva, pois, para além de uma formação acadêmica, profissional e específica, os mesmos oferecem condições e oportunidades para exercer um pensamento crítico e cidadão, reconstruindo e delineando visões, valores, conhecimentos e concepções mais evoluídas de homem, sociedade e democracia.

\subsection{A licenciatura sob o enfoque científico: iniciativas e políticas de acesso e permanência}

A partir da década de 1990 entrou em cena um novo olhar sobre a formação docente no Brasil, priorizando um professor que domine os processos de concepção e execução indissociáveis e que pense a sua prática. Nesse sentido, Severino (2007) traz a importância do ensino aliado à pesquisa no processo de construção do conhecimento como inerente à formação superior, na qual os acadêmicos possam discordar, concordar, problematizar, investigar, propor e mormente construir, mas, para isso, é preciso se atentar para o que Libâneo, Oliveira e Toschi (2012) trazem quando ressaltam a imprescindibilidade da valorização docente e sua experiência e o incentivo à cientificidade na sua formação.

Quando se fala sobre pesquisa no ensino, a sua eficácia aliada ao ensino, a junção teoria-prática e o binômio processoproduto de conhecimento, é relevante, e até mesmo oportuno, colocar à baila iniciativas e políticas de consolidação do curso de Licenciatura que reforçam cada vez mais a cientificidade e importância da mesma no constructo educativo e social, procurando também chamar atenção para a escolha da mesma, bem como seu acesso e permanência.

Um exemplo dessas políticas é o Programa Universidade para Todos (PROUNI) do governo federal criado em 2004 e regido pela Lei 11.096 de 2005, que oferece bolsas de ensino integrais e parciais a estudantes em instituições privadas de ensino em diversos setores e tipos de formação superior, e que no tocante à formação de professores professa nas suas prioridades a concessão de bolsas para cursos de licenciatura no inciso III do artigo $2^{\circ}$ aos [...] professor[es] da rede pública de ensino, para os cursos de licenciatura, normal superior e pedagogia, destinados à formação do magistério da educação básica, independentemente da renda [...]" (MEC,2005, p. 1).

Somando-se ao rol de iniciativas governamentais e políticas é importante ressaltar o Fundo de Financiamento ao Estudante de Ensino Superior (FIES) criado em 1999 e regulamentado pela Lei 10.260 de 2001, que após passar por algumas reformulações passou a não exigir mais a pessoa do fiador como garantia de pagamento pelo financiamento, o que também facilita o acesso e permanência na licenciatura assim como o PROUNI.

Interessante também, apontar programas como o de residência pedagógica e os de iniciação científica na graduação, subsidiados por agências de fomento e em alguns casos pela própria instituição de ensino superior, que possibilitam ao graduando, aperfeiçoar a sua profissionalidade e iniciar-se na vida científica e investigativa, podendo fazer paralelos entre conhecimentos já perpetuados e os que ainda estão em construção, o que viabiliza construir-se enquanto sujeito no universo das 
contradições encontradas nessa tessitura (Marx, 2011) e corporeificar a sua condição e sujeito como construção histórica (Arruda, 2017).

Especificamente na licenciatura, encontra-se em vigência, entre caminhos e descaminhos, desde o ano de 2006, o Programa Institucional de Bolsas de Iniciação à Docência (PIBID) subsidiado pela Coordenação de Aperfeiçoamento de Pessoal de Nível superior em parceria com o governo federal. Segundo Burggrever e Mormul (2017, p. 98):

O Programa Institucional de Bolsa de Iniciação à Docência (Pibid) teve início no ano de 2006, nas Instituições Federais de Ensino e no ano de 2009 foi introduzido como política de Estado relacionado à formação de professores em todo o país, por meio do Decreto ${ }^{\circ} 6755$ de 29 de janeiro de 2009 [...]. O Pibid tem por objetivo incentivar a iniciação à docência por meio de ações didático-pedagógicas que aproximem o licenciando da realidade escolar, articulando ensino superior e educação básica. A partir da Portaria Normativa n ${ }^{\circ} 38$, de 12 de dezembro de 2007, da Capes [...] e da ação conjunta entre Ministério da Educação [...], sua Secretaria de Educação Superior (SESU) e do Fundo Nacional de Desenvolvimento da Educação (FNDE), o programa se consolidou.

Para os cursos de licenciatura foi um ganho inenarrável, uma vez que, proporciona o conhecimento acerca do ambiente escolar, realiza a integração universidade-escola-comunidade, e, mais que isso, a problematização, reflexão e proposição de alternativas na melhoria do ensino como atividade-fim da escola.

Dessarte, ao elencar ligeiramente algumas iniciativas, programas e políticas de iniciativa pública, é notório que a formação docente hoje, ainda que necessite de muitas mudanças e rearranjos, já avançou consideravelmente em termos de acesso e permanência dos acadêmicos, criando minimamente condições de entrada e fazendo com que a estadia durante a etapa de formação acadêmica seja sob o enfoque da ciência e não mais apenas de transmissão de conteúdos desvinculados, oportunizando ao licenciando conhecer os produtos científicos através do ensino, dando-lhe condições e ferramentas para construí-los também sob uma perspectiva de complexidade (Morin, 2015).

\section{Considerações Finais}

Ao percorrer alguns momentos da história de formação de professores, focalizando as divergências que aconteceram ao longo do tempo quanto ao escopo do curso de licenciatura, colocar em xeque as características que a identificam em relação aos outros cursos de formação superior e apontar as políticas atuais de acesso, permanência e produção de conhecimento, pôde-se perceber o quão tênue foi esse processo de consolidação da formação de professores, em que, ora ressalta-se a importância apenas dos produtos, ora promove-se a riqueza do discurso da construção do conhecimento.

Esse movimento de vai e vem, ressalta a plasticidade embutida na formação de professores e a ausência de um discurso eficaz de valorização da licenciatura perpetuado na história, apesar de hoje termos políticas que estão reescrevendo, a passos lentos, a identidade da formação docente na contramão das políticas restritivas e sucateadoras da educação.

Nesse sentido, hodiernamente, é possível enxergar, sem a necessidade de lentes de aumento, a identidade da docência em relação às outras profissões capacitadas por outros cursos superiores, e é claro que, isso não quer dizer que as políticas salariais e condições de trabalho estão equitativas para todas, é preciso deixar, sem margem para dubiedade de sentido, que ainda temos um longo percurso a fazer em relação a isso, mas no que tange à entrada, à escolha pelo magistério, a qualidade dos cursos, as políticas de permanência, os programas que possibilitam a visualização da licenciatura como um constructo científico e demais aspectos que não foram minuciosamente deslindados aqui, já se consegue evidenciar um saldo positivo.

Assim, recomendamos este trabalho para aqueles que desejam fazer uma breve incursão sobre os cursos de licenciatura e as políticas de formação docente advindas de legislações importantes que se concebem num campo de disputa. Nos eximimos aqui de qualquer pretensão de se constituir ponto chegada em alguma questão, ao contrário, prezamos por lançar breves discussões para que as lacunas sejam revisitadas e aperfeiçoadas dentro do universo acadêmico e científico. 
Research, Society and Development, v. 10, n. 9, e55010918405, 2021

(CC BY 4.0) | ISSN 2525-3409 | DOI: http://dx.doi.org/10.33448/rsd-v10i9.18405

\section{Referências}

Arruda, R. (Org.) (2017). Trabalho, subjetividade e formação humana em tempos de reestruturação do capitalismo. Rio de Janeiro: UERJ - LPP.

Burggrever, T., \& Mormul, N. M. (2017). A importância do PIBID na formação inicial de professores: um olhar a partir do subprojeto de geografia da UNIOESTE-Francisco Beltrão. Revista de Ensino de Geografia, 8 (15), 98-122.

Correa, P. M. (2011). O paradigma da educação brasileira nas décadas de 70, 80 e 90. Artigonal. http://www.artigonal.com/ciencia-artigos/o-paradigma-daeducacao-brasileira-nas-decadas-de-70-80-e-90-4230215.html

Freitas, H. C. L. de. (2002). Formação de professores no Brasil: 10 anos de embate entre projetos de formação. Revista Educação e Sociedade, 23 (80), 136167.

Godoy. A. S. (1995). Pesquisa qualitativa: tipos fundamentais. Revista de administração de Empresas, 35 (3), 20 -29.

https://www.scielo.br/j/rae/a/ZX4cTGrqYfVhr7LvVyDBgdb/?lang=pt\&format=pdf

Guedes, N. C., \& Ferreira, M. S. (2002). História e construção da profissionalização nos cursos de licenciaturas. Website da Sociedade Brasileira de História da Educação. http://sbhe.org.br/novo/congressos/cbhe2/pdfs/Tema3/3112.pdf

Lei 4.024, de 20 de dezembro de 1961. (1961). Fixa as Diretrizes e Bases da Educação Nacional. Brasília, DF.

Lei n. 5.692, de 11 de agosto de 1971. (1971). Fixa Diretrizes e Bases para o ensino de $1^{\circ}$ e $2^{\circ}$ graus, e dá outras providências. República Federativa do Brasil, Brasília, DF.

Lei $n^{o}$ 10.260, de 12 de julho de 2001. (2001). Dispõe sobre o Fundo de Financiamento ao estudante do Ensino Superior e dá outras providências. Brasília, DF.

Lei $n^{\circ} 11.096$, de 13 de janeiro de 2005. (2005). Institui o Programa Universidade para Todos - PROUNI, regula a atuação de entidades beneficentes de assistência social no ensino superior; altera a Lei ${ }^{\circ}$ 10.891, de 9 de julho de 2004, e dá outras providências. Brasília, DF.

Libâneo, J. C. (2011). Adeus professor, adeus professora?: novas exigências educacionais e profissão docente. (13a ed.). São Paulo: Cortez.

Libâneo, J. C., Oliveira, J.F. de., \& Toschi, M. S. (2012). Educação escolar: políticas, estrutura e organização. (10a ed.). São Paulo: Cortez.

Luckesi, C.C. (2011). Filosofia da educação. (3a ed). São Paulo: Cortez.

Martins, J. (2010). A pesquisa qualitativa. In FAZENDA, I. (Org). Metodologia da pesquisa educacional. (12a ed.). São Paulo: Cortez.

Marx, K. (2011). O 18 Brumário de Luís Bonaparte. São Paulo: Boitempo.

Morin, E. (2015). Introdução ao pensamento complexo. (5a ed.). Porto Alegre: Sulina.

Penin, S. T. de. S. (2002). Profissão Docente. Salto para o futuro, (14), 2-9. http://portaldoprofessor.mec.gov.br/storage/materiais/0000012181.pdf

Pereira, J. E. D. (1999). As licenciaturas e as novas políticas educacionais para a formação docente. Revista Educação e Sociedade, 20 (68), $109-125$.

Pereira, J. E. D. (2000). Formação de professores: pesquisa, representações e poder. (1a ed.). Belo Horizonte: Autêntica,

Saviani, D. (1983). Educação: do senso comum à consciência filosófica. (3a ed.). São Paulo: Cortez.

Severino, A. J. (2007). Metodologia do trabalho científico. (23a ed.). São Paulo: Cortez.

Silveira, V. F. da., \& Silva; I. F. (2009). Graduação, a escolha entre licenciatura e bacharelado. Website da Universidade Estadual de Londrina. http://www.uel.br/grupoestudo/gaes/pages/arquivos/GT4\%20Artigo\%20Vanessa\%20Ferreira\%20Graduacao\%20a\%20escolha.pdf

Souza, H. J. de. (2014). Como se faz análise de conjuntura. (34a ed). Petrópolis - RJ: Vozes. 